Published in final edited form as:

Exp Eye Res. 2012 September ; 102C: 70-75. doi:10.1016/j.exer.2012.06.009.

\title{
Human ocular biometry
}

\author{
Robert C. Augusteyn a,b,c, ${ }^{*}$, Derek Nankivil ${ }^{c}$, Ashik Mohamed ${ }^{\mathrm{a}, \mathrm{b}, \mathrm{d}}$, Bianca Maceo ${ }^{\mathrm{c}, \mathrm{e}}$, Faradia \\ Pierre $^{\mathrm{c}}$, and Jean-Marie Parel $\mathrm{I}^{\mathrm{a}, \mathrm{c}, \mathrm{e}}$ \\ aVision Cooperative Research Centre, Brien Holden Vision Institute, Sydney, Australia \\ bSchool of Optometry and Vision Science, University of NSW, Sydney, Australia \\ 'Ophthalmic Biophysics Center, Bascom Palmer Eye Institute, University of Miami Miller School \\ of Medicine, Miami, FL 33136, USA \\ dProf. Brien Holden Eye Research Centre, L V Prasad Eye Institute, Hyderabad, India \\ eBiomedical Optics and Laser Laboratory, Department of Biomedical Engineering, University of \\ Miami College of Engineering, Coral Gables, FL 33146, USA
}

\begin{abstract}
The aim of this study was to examine growth of the human eye globe and cornea from early in gestation to late in adult life. Globe antero-posterior length, horizontal and vertical diameters, corneal horizontal and vertical (white to white) diameters and posterior pole to limbus distances were measured using digital calipers $( \pm 0.01 \mathrm{~mm})$ in 541 postmortem eyes. Additional pre- and postnatal data for some of the dimensions were obtained from the literature. All dimensions examined increase rapidly during prenatal development but postnatal growth differs. Growth of globe antero-posterior length, vertical and horizontal diameters as well as corneal vertical and horizontal diameters stops within 1 year after birth. Logistic analysis is consistent with an asymptotic prenatal growth mode and no further growth after its completion around 1 year after birth. Horizontal and vertical globe diameters are the same at all ages but the corneal horizontal diameter is always larger than the vertical diameter. No differences could be detected between males and females in any of the ocular dimensions. Globe and corneal growth take place primarily during the prenatal growth mode and dimensions reach their maxima, shortly after birth. It is suggested that cessation of a growth stimulating signal at birth marks the end of the prenatal growth mode and that the small increases over the next year are due to cells already stimulated. Male and female eyes of the same age have the same globe and cornea dimensions.
\end{abstract}

\section{Keywords}

human; ocular growth; corneal dimensions; globe dimensions; gender

\section{Introduction}

Detailed knowledge of ocular dimensions (globe, cornea and lens) and how they change with age are of considerable value in understanding ocular growth and the development of pathologies such as myopia and presbyopia. Surgical procedures for improving vision, such

\footnotetext{
${ }^{\star}$ A preliminary report on some of the data was presented at the annual meetings of the Association for Research in Vision and Ophthalmology, Fort Lauderdale in May 2010 and 2012.

(C) 2012 Published by Elsevier Ltd.

*Corresponding author. Vision CRC, 30 Melcombe Rd, Ivanhoe, Victoria 3079, Australia. Tel.: +61 394991838.

B.Augusteyn@ier.org.au, raugustn@bigpond.net.au (R.C. Augusteyn).
} 
as intraocular lens (IOL) implantation and refilling of lens capsular bags (Phaco-Ersatz) (Nishi et al., 1993; Koopmans et al., 2006; Parel et al., 1986) would also benefit from such information.

There have been numerous studies in which some ocular dimensions, such as lens thickness, or axial length were measured. Such measurements have generally been made in vivo, with the slit lamp or ultrasound, and have required correction for optical or sonic distortion (e.g. Atchison et al., 2008; Dubbelman et al., 2001). Differences in the corrections and measurement techniques have led to variations in the reported dimensions. Furthermore, many of the previous studies were concerned with specific issues and considered only a limited age group, such as myopia development in young children. Very few considered the relationship between different dimensions such as the cornea, lens and globe. As a result there is a paucity of data, variability in those that are available and some questions regarding extrapolation of limited age data to the whole of the life span.

Measurement of global dimensions and, until recently, lens diameter can only be performed in vitro. Many of the measurements of other ocular dimensions would be easier and more accurate if also conducted in vitro. However, because of the limited availability of ex vivo human tissues, very few data have been obtained on the globe and lens. As part of a longterm study on factors contributing to the development of presbyopia (Augusteyn et al., 2011), we have collected a large body of in vitro data on human globe, cornea and lens dimensions. Although the vast majority of these were from adults, data for prenatal and juvenile eyes are available in the literature. The combination has provided us with a comprehensive data set which offers the possibility of exploring various aspects of ocular growth over the whole of the human life span.

\section{Methods}

Post-mortem human eyes from donors, ranging in age from 1 day to 104 years, were provided by the Florida Lions Eye Bank, Miami, USA and the Ramayamma International Eye Bank, Hyderabad, India. The eyes were obtained and used in compliance with the guidelines of the Declaration of Helsinki for research involving the use of human tissue. The cause and time of death, time to enucleation, donor age and gender were available for most eyes. Following a common protocol described previously (Augusteyn et al., 2011), diseased eyes and eyes with obvious anomalies were excluded, leaving 541 eyes. In a small number of cases, where the donor globe was flaccid, the globe was re-inflated by injecting balanced salt solution (BSS, Alcon Inc, Fort Worth, TX) into the vitreous cavity, via an oblique selfsealing insertion of a 30 ga needle through the posterior sclera, until IOP, assessed by palpitation (Birnbach and Leen, 1998) reached about $20 \mathrm{mmHg}$. The assessment of tonus and injection of salt solution were performed by an experienced ophthalmic surgeon. Small variations in the final pressure in a fully extended globes would be unlikely to affect the measurements since preliminary tests for a study on scleral buckling, conducted in our laboratory (Nakagawa et al., 2000), had shown that equatorial diameter was unchanged with pressures ranging from 6 to $>90 \mathrm{~mm}$.

Measurements of global and corneal (white to white) dimensions were performed, after removing surrounding fat and extra-ocular muscle stumps, using digital calipers $(0.01 \mathrm{~mm}$ readout, INOX IP54 Caliper, Micro Precision Calibration Inc., California and 500-195-20, Mitutoyo America Co, Aurora IL) as first described by Nakagawa et al. (2000). Each eye was examined and pairs were not averaged when both eyes from one donor were available. The repeatability of the measurements was tested in a separate study (Taneja M., et al., Invest Ophthalmol Vis Sci. 2012; 53:E-Abstract 4908). The dimensions measured are shown in Fig. 1.

Exp Eye Res. Author manuscript; available in PMC 2013 September 01. 
Additional data, predominantly foetal and early childhood, were obtained from the literature for some of the dimensions. Globe dimensions were found in articles by Ehlers (1968), Harayama et al. (1980), Huang (1987) and Lim et al. (1998). Corneal dimensions came from al-Umran and Pandolfi (1992), Denis et al. (1998), Ehlers (1968), Harayama et al. (1980), Huang (1987), Kirwan et al. (2005), Ko et al. (2001), Kwak et al. (1988), Liu (1992), Rufer et al. (2005) and Savini et al. (2011). With the exception of the Orbscan corneal measurements of Rufer et al. (2005) all published dimensions were obtained with Castroviejo $( \pm 0.5 \mathrm{~mm})$, Jameson-type $( \pm 0.25 \mathrm{~mm})$ or Vernier $( \pm 0.05 \mathrm{~mm})$ calipers.

Plots of data copied from the literature were magnified at least ten-fold and the coordinates for the points were measured to the nearest $0.5 \mathrm{~mm}$, before being converted to the axis units. The maximum error associated with these measurements was estimated to be $<1 \%$.

Data were examined using various algorithms commonly in use for analysing growth processes. The logistic equation in its linearized form [log (Dimension) $=\log$ (Maximum dimension) $-k /$ Age] was found most suitable, where ' $k$ ' is the growth constant. Student's $t$ statistics were used to compare different biometric parameters and to test for significance of regression coefficients.

\section{Results}

Postnatal globe and cornea dimensions (Fig. 1) were obtained from 541 eyes in the present study. Up to 200 additional data for some of the parameters of interest, including all of those from prenatal donors, were gleaned from the literature. To simplify presentation and interpretation, the data from eyes younger than 2 years post-conception are displayed differently from those over 2 years from conception.

\subsection{Globe}

The antero-posterior (AP) lengths and the horizontal $(H)$ diameters of isolated globes, as a function of age since conception, are presented in Fig. 2. The AP lengths and the horizontal diameters all increase rapidly through foetal life and more slowly until about 1 year postnatal (1.74 years since conception), but, thereafter, appear to be constant. Linear regression analysis of the older ( $>2$ years) eye data suggests that the AP length might increase at $0.0019 \pm 0.0037 \mathrm{~mm} /$ year $(p=0.304)$ and $H$ at $0.0016 \pm 0.0038 \mathrm{~mm} /$ year $(p=$ 0.420 ) while the vertical diameter $(V)$ might decrease at $-0.0016 \pm 0.0039 \mathrm{~mm} /$ year $(p=$ 0.431 ). However, these rates were statistically not significantly different from zero, leading to the conclusion that none of the globe dimensions change after completion of the asymptotic growth within 1 year of birth (1.74 years post-conception). For all eyes between 2 and 100 years after conception, the means for the horizontal and vertical diameters are $24.26 \pm 0.96 \mathrm{~mm}(n=518)$ and $24.16 \pm 0.97 \mathrm{~mm}(n=510)$, respectively. The external AP globe length is slightly but significantly greater than the globe diameter $(p<0.027)$, with a mean of $24.44 \pm 1.03 \mathrm{~mm}(n=509)$. There was no significant difference between the horizontal and vertical globe diameters $(p>0.54)$. Where both measurements were available for the same eye, the ratio of $H / V$ for 507 eyes, older than 2 years, was $1.003 \pm 0.032$. Each of the adult globe dimensions measured in the present study is around $2.5 \%$ greater than previous estimates (Park and Karesh, 2006).

The early growth in globe dimensions can be well described with a logistic function, consistent with asymptotic growth. A linearized logistic plot of the AP lengths (log AP length vs 1/age) is shown in Fig. 3. All of the prenatal data and those from postnatal eyes less than two years after conception fall on a single straight line with a slope of 0.165 years (the growth constant), indicating these are the outcomes of a single growth mode. 
Backwards extrapolation of the logistic lines of best fit, such as that in Fig. 3, was used to determine where the young trend lines met the adult trend lines (constant). The intersection points indicated that the above maximum globe dimensions were all reached shortly after 1 year post conception.

\subsection{Cornea}

Both vertical and horizontal corneal diameters (white to white) were determined for 513 eyes and a further 156 horizontal diameters, mainly from young and foetal eyes, were obtained from the literature. The data are presented in Fig. 4. As with the globe dimensions, corneal growth is rapid during foetal life and appears to cease shortly after birth. In agreement with the overviews by Maurice (1969) and Weale (1982) we found that $H$ is always greater than $V$. For all eyes examined, prenatal to 90 years old, $V / H$ averaged $0.95 \pm$ 0.03 . No differences in this ratio were observed with age, including the prenatal period. The values for eyes older than 2 years were $11.81 \pm 0.65(n=503)$ and $11.26 \pm 0.64(n=496)$ mm for $H$ and $V$, respectively.

Logistic analysis of the horizontal diameters is shown in Fig. 5. All of the prenatal data and those from early postnatal life can again be described with a single straight line. The growth constant of 0.174 years is very close to that observed with globe growth ( 0.165 years). Backward extrapolation of the logistic line in Fig. 5 to where it met the adult trend line indicated that the maximum diameter was reached at $\sim 1.2$ years post-conception. The same conclusions were reached from the vertical diameter changes.

The posterior pole-limbus length data are presented in Fig. 6. No data were obtained for prenatal tissues in the current study and none could be found in the literature for this dimension at any age. It would appear that, like the other globe dimensions, the length probably reaches its maximum before 2 years, and averages $22.0 \pm 1.0 \mathrm{~mm}$, thereafter. Logistic analysis was not feasible because of the lack of data from younger eyes.

\subsection{Gender}

Gender information was available for many of the eyes. The influence of gender on globe AP length and corneal horizontal diameter measured in the current study is presented in Fig. 7. No differences were detected between males and females at any age in the two parameters shown, nor in the globe vertical and horizontal diameters, corneal vertical diameter and posterior pole-limbus distance.

\section{Discussion}

In this study we have collected a substantial body of in vitro data on growth of the eye in human adults. In combination with data on young eyes obtained from the literature, it is possible to examine growth patterns more closely.

Our analyses indicate that growth of the globe, including the cornea, takes place predominantly before birth and ceases within a year, or so, after birth. This differs from the apparently accepted view that scleral growth continues throughout childhood, with adult size attained around age 14-18 years (Dawson et al., 2006; Park and Karesh, 2006) but agrees with previous reports that corneal growth is complete within 3 years after birth (Dawson et al., 2006; Duke-Elder and Wybar, 1961; Weale, 1982). The similarity of the globe and cornea logistic growth constants for the prenatal and early postnatal period suggests that these may be controlled through the same regulatory mechanism.

Our observations are consistent with the formation of a fully functional., emmetropic, eye not long after birth. The ability to focus accurately, track moving objects, judge distance and 
see colour all develop within the first year. Globe and corneal growth are completed by then, well before other parts of the body reach their optimal sizes. For example, brain growth, as judged from its weight, is not complete until late adolescence (Dekaban and Sadowsky, 1978) while head size (circumference) also continues to increase, at least until age 18 years (Eichorn and Bayley, 1962; Nellhaus, 1968). Thus early in life, the eye is relatively large. This is responsible for the well-recognized wide-eyed appeal of the young child, as well as the young of other species.

The completion time observed in the present study is similar to the time of transition from asymptotic to linear growth observed for human lens wet weight (Augusteyn, 2007). It seems likely that the same prenatal signal will be involved in both cases but, unlike the cornea and sclera, the lens continues to grow larger during all of postnatal life. In addition to the increase in wet weight, indicative of continual growth, lens diameter also increases continuously (Augusteyn, 2010). However, lens thickness changes are more complex. From birth to early adulthood, human lens thickness appears to decrease, as part of lens remodelling, before increasing during adult life. Further information is needed on lens dimensions early in life in order to assess the significance of these complex changes and their contributions to the optical performance of the eye.

An interesting observation arising from the current study is that growth in axial length (outer corneal to inner retinal surfaces) appears to lag behind that of the globe AP length. Comparison with literature values for axial length suggests that the difference between globe AP length and axial length is about $1.3 \mathrm{~mm}$ at 2 years post conception. Thereafter, axial length continues to increase (Atchison et al., 2008; Leighton and Tomlinson, 1972; Ooto et al., 2011; Stone et al., 2004; and Wong et al.,; 2001b) while globe AP length remains constant, so that by 90 years, the difference has decreased to $0.8 \mathrm{~mm}$. The increase with age in the axial length is probably a reflection of the decrease in scleral thickness (Vannas and Teir, 1960; Weale, 1963) which results in an increase in vitreous chamber depth. The combined corneal and scleral thickness probably account for the $0.8 \mathrm{~mm}$ difference in the old eye.

In a recent review (Park and Karesh, 2006), it was stated that the globe horizontal diameter is slightly greater than the vertical. Some earlier studies (reviewed by Weale, 1982) also appear to suggest this, but no statistical evaluations were performed. We find no indication of such a difference. The average diameters for all eyes over 2 years of age were $24.26 \pm$ 0.96 and $24.16 \pm 0.97 \mathrm{~mm}$, respectively for $V$ and $H$. Where both measurements were available for the same eye, the ratio of $V / H$ averaged $1.003 \pm 0.032$. Although the standard deviations are somewhat large, reflecting the inter- and intra-operator variations observed with ocular measurements (Taneja M., et al., Invest Ophthalmol Vis Sci. 2012; 53:EAbstract 4908) a similar variability did not preclude us from observing the difference between corneal $H$ and $V$. It has also been reported that $H$ is 7-8\% larger than $V$ very early in gestation and that the $V / H$ ratio increases during prenatal development reaching 1.0 at birth (Harayama et al., 1981). However, these data were obtained with eyes which had been fixed, making it difficult to assess their relevance to the fresh unfixed eye. No prenatal increase was observed for the $V / H$ ratio in a study by Huang (1987).

It should be noted that the measurement techniques used in the present study, as well as those in the cited literature, require contact with the ex vivo globe's soft tissue. This may cause some deformation and therefore may limit the accuracy, preventing assessment of differences smaller than $0.1 \mathrm{~mm}$ (Taneja M., et al., Invest Ophthalmol Vis Sci. 2012; 53:EAbstract 4908). More accurate, non-contact techniques need to be developed to permit measurement of smaller differences. 
Comparison of the globe dimensions and posterior pole-limbus measurements indicate that the isolated eye can be considered to be a quasi-spheroid (globe) intersected by an oblate spheroid (cornea). In the adult, the spherical globe has a diameter of near $24.2 \mathrm{~mm}$ and the cornea has vertical and horizontal diameters of around 11.8 and $11.2 \mathrm{~mm}$, respectively. How these ex vivo dimensions relate to the in vivo shape of the globe, which is under the influence of the ocular muscles, cannot be assessed at present and will require information from non-invasive techniques such as $1.5 \mathrm{~T}$ magnetic resonance imaging (MRI) that has a measured precision of $0.31 \mathrm{~mm}$ (Hermans et al., 2009).

Unlike other biometric observations on humans, such as weight, height etc, we find no gender differences for the external globe and corneal dimensions at any age. This was also found to be the case for lens growth in humans as well as in several other species (Augusteyn, 2007, 2008). Thus, it would appear that the size of the human eye and its components are the same in males and females. This is not really surprising, since, unlike an increase in body size, a small difference in eye size would impart no obvious benefit when interacting with the environment. However, some reports (Laws et al., 1994; Zadnik et al., 2003) suggest axial length in boys is greater than that in girls (Male/female $=1.017 \pm$ $0.005)$. This may be related to differences in height. Whether this extends to adults is not known, although gender differences were described in some earlier reports (reviewed by Weale, 1982). A difference was observed in adult rhesus monkeys (Fernandes et al., 2003). Further research is required to determine if the gender difference persists in humans and what advantage this might confer.

In conclusion, our analyses indicate that growth of the globe, including the cornea, takes place predominantly during prenatal development and ceases within a year after birth. Subsequent maturation of the visual system must, therefore, involve only internal ocular components such as the lens and retina. Studies on the growth of the lens are continuing in our laboratories.

\section{Acknowledgments}

This work was supported, in part, by NIH Research Grants R01EY014225 and P30EY14801 (Center Grant), the Australian Federal Government CRC Scheme through the Vision Cooperative Research Centre, an NRSA Individual Predoctoral Fellowship 1F31EY021444 [BM], the Florida Lions Eye Bank, an unrestricted grant from Research to Prevent Blindness, and the Henri and Flore Lesieur Foundation (JMP). The authors are grateful for the assistance of Elizabeth Fout-Carazza and her team at the Florida Lions Eye Bank for gathering and donating tissues and donor data. Esdras Arieta, David Borja, Mukesh Taneja, Pesala Veerendranath, Noel Ziebarth and the OBC team participated in various ways in some of the data collection. Karam Alawa helped with the literature searches.

\section{References}

al-Umran KU, Pandolfi MF. Corneal diameter in premature infants. Br J Ophthalmol. 1992; 76:292293. [PubMed: 1390512]

Atchison DA, Markwell EL, Kasthurirangan S, Pope JM, Smith G, Swann PG. Age-related changes in optical and biometric characteristics of emmetropic eyes. J Vis. 2008; 8:1-20. [PubMed: 18484868]

Augusteyn RC. Growth of the human eye lens. Mol Vis. 2007; 13:252-257. [PubMed: 17356512]

Augusteyn RC. Growth of the lens: in vitro observations. Clin Exp Optom. 2008; 91:226-239. [PubMed: 18331361]

Augusteyn RC. On the growth and internal structure of the human lens. Exp Eye Res. 2010; 90:643654. [PubMed: 20171212]

Augusteyn RC, Mohamed A, Nankivil D, Veerendranath P, Arrieta E, Taneja M, Manns F, Ho A, Parel JM. Age-dependence of the optomechanical responses of ex vivo human lenses from India and the USA, and the force required to produce these in a lens stretcher: the similarity to in vivo disaccommodation. Vision Res. 2011; 51:1667-1678. [PubMed: 21658404] 
Birnbach CD, Leen MM. Digital palpation of intraocular pressure. Ophthalmic Surg. Laser. 1998; 29:754-757.

Dawson, DG.; Watsky, MA.; Geroski, DH.; Edelhauser, HF. Cornea and sclera. In: Tasman, W.; Jaeger, EA., editors. Duane's Foundations of Clinical Ophthalmology. Lippincott Williams \& Wilkins; 2006.

Dekaban AS. Changes in brain weights during the span of human life: relation of brain weights to body heights and body weights. Ann Neurol. 1978; 4:345-356. [PubMed: 727739]

Denis D, Burguiere O, Burillon C. A biometric study of the eye, orbit, and face in 205 normal human fetuses. Invest Ophthalmol Vis Sci. 1998; 39:2232-2238. [PubMed: 9804130]

Dubbelman M, van der Heijde GL, Weeber HA. The thickness of the aging human lens obtained from corrected Scheimpflug images. Optom Vis Sci. 2001; 78:411-416. [PubMed: 11444630]

Duke-Elder, S.; Wybar, K. The eye. In: Duke-Elder, S., editor. The Anatomy of the Visual System. CV Mosby; St Louis: 1961. p. 75-386.

Ehlers N, Matthiessen ME, Andersen H. The prenatal growth of the human eye. Acta Ophthalmol (Copenh). 1968; 46:329-349. [PubMed: 5755727]

Eichorn DH, Bayley N. Growth in head circumference from birth through young adulthood. Child Dev. 1962; 33:257-271. [PubMed: 13889573]

Fernandes A, Bradley DV, Tigges M, Tigges J, Herndon JG. Ocular measurements throughout the adult life span of rhesus monkeys. Invest Ophthalmol Vis Sci. 2003; 44:2373-2380. [PubMed: 12766033]

Harayama K, Amemiya T, Nishimura H. Development of the cornea during fetal life: comparison of corneal and bulbar diameter. Anat Rec. 1980; 198:531-535. [PubMed: 7457942]

Harayama K, Amemiya T, Nishimura H. Development of the eyeball during fetal life. J Pediatr Ophthalmol Strabismus. 1981; 18:37-40. [PubMed: 7264857]

Hermans EA, Pouwels PJW, Dubbelman M, Kuijer JPA, van der Heijde RGL, Heethaar RM. Constant volume of the human lens and decrease in surface area of the capsular bag during accommodation: an MRI and Scheimpflug Study. Invest Ophthalmol Vis Sci. 2009; 50:281-289. [PubMed: 18676625]

Huang XZ. Measurements of the fetal eyeball and its pattern of growth. Zhonghua Yan Ke Za Zhi. 1987; 23:304-305. [PubMed: 3127184]

Kirwan C, O'Keefe M, Fitzsimon S. Central corneal thickness and corneal diameter in premature infants. Acta Ophthalmol Scand. 2005; 83:751-753. [PubMed: 16396656]

Ko MK, Park WK, Lee JH, Chi JG. A histomorphometric study of corneal endothelial cells in normal human fetuses. Exp Eye Res. 2001; 72:403-409. [PubMed: 11273668]

Koopmans SA, Terwee T, Glasser A, Wendt M, Vilipuru AS, van Kooten TG, Norrby S, Haitjema HJ, Kooijman AC. Accommodative lens refilling in rhesus monkeys. Invest Ophthalmol Vis Sci. 2006; 47:2976-2984. [PubMed: 16799042]

Kwak NH, Kim MS, Kim JH. A statistical study on the corneal diameter. J Korean Ophthalmol Soc. 1988; 29:245-249.

Laws DE, Haslett R, Ashby D, O’Brien C, Clark D. Axial length biometry in infants with retinopathy of prematurity. Eye (Lond). 1994; 8(Pt 4):427-430. [PubMed: 7821466]

Leighton DA, Tomlinson A. Changes in axial length and other dimensions of the eyeball with increasing age. Acta Ophthalmol (Copenh). 1972; 50:815-826. [PubMed: 4678871]

Lim SJ, Kang SJ, Kim HB, Kurata Y, Sakabe I, Apple DJ. Analysis of zonular-free zone and lens size in relation to axial length of eye with age. J Cataract Refract Surg. 1998; 24:390-396. [PubMed: 9559477]

Liu YF. A study on the diametric growth of the cornea in Chinese children. Zhonghua Yan Ke Za Zhi. 1992; 28:360-362. [PubMed: 1306474]

Maurice, D. Cornea and sclera. In: Davson, H., editor. Physiology of the Eye. Little, Brown and Co; Boston: 1969. p. 14-15.

Nakagawa N, Murray TG, Parel J-M, Oshima K. Effect of scleral shortening on axial length. Arch Ophthalmol. 2000; 118:965-968. [PubMed: 10900111] 
Nellhaus G. Head circumference from birth to eighteen years. Practical composite international and interracial graphs. Pediatrics. 1968; 41:106-114. [PubMed: 5635472]

Nishi O, Nakai Y, Yamada Y, Mizumoto Y. Amplitudes of accommodation of primate lenses refilled with two types of inflatable endocapsular balloons. Arch Ophthalmol. 1993; 111:1677-1684. [PubMed: 8155039]

Ooto S, Hangai M, Tomidokoro A, Saito H, Araie M, Otani T, Kishi S, Matsushita K, Maeda N, Shirakashi M, Abe H, Ohkubo S, Sugiyama K, Iwase A, Yoshimura N. Effects of age, sex, and axial length on the three-dimensional profile of normal macular layer structures. Invest Ophthalmol Vis Sci. 2011; 52:8769-8779. [PubMed: 21989721]

Parel JM, Gelender H, Trefers WF, Norton EW. Phaco-Ersatz: cataract surgery designed to preserve accommodation. Graefes Arch Clin Exp Ophthalmol. 1986; 224:165-173. [PubMed: 3949191]

Park, DJ.; Karesh, J. Topographic anatomy of the eye: an overview. In: Tasman, W.; Jaeger, EA., editors. Duane's Foundations of Clinical Ophthalmology. Lippincott Williams \& Wilkins; 2006.

Rufer F, Schroder A, Erb C. White-to-white corneal diameter: normal values in healthy humans obtained with the Orbscan II topography system. Cornea. 2005; 24:259-261. [PubMed: 15778595]

Savini G, Carbonelli M, Barboni P, Hoffer KJ. Repeatability of automatic measurements performed by a dual Scheimpflug analyzer in unoperated and post-refractive surgery eyes. J Cataract Refract Surg. 2011; 37:302-309. [PubMed: 21241913]

Stone RA, Quinn GE, Francis EL, Ying GS, Flitcroft DI, Parekh P, Brown J, Orlow J, Schmid G. Diurnal axial length fluctuations in human eyes. Invest Ophthalmol Vis Sci. 2004; 45:63-70. [PubMed: 14691155]

Vannas S, Teir H. Observations on structures and age changes in the human sclera. Acta Ophthalmol (Copenh). 1960; 38:268-279. [PubMed: 13855196]

Weale, RA. The Aging Eye. Harper \& Row; New York: 1963.

Weale, RA. A Biography of the Eye; Development, Growth, Age. Lewis \& Co; London: 1982.

Wong TY, Foster PJ, Ng TP, Tielsch JM, Johnson GJ, Seah SK. Variations in ocular biometry in an adult Chinese population in Singapore: the Tanjong Pagar Survey. Invest Ophthalmol Vis Sci. 2001; 42:73-80. [PubMed: 11133850]

Zadnik K, Manny RE, Yu JA, Mitchell GL, Cotter SA, Quiralte JC, Shipp M, Friedman NE, Kleinstein RN, Walker TW, Jones LA, Moeschberger ML, Mutti DO. Collaborative Longitudinal Evaluation of, E., Refractive Error Study, G. Ocular component data in schoolchildren as a function of age and gender. Optom Vis Sci. 2003; 80:226-236. [PubMed: 12637834]

Exp Eye Res. Author manuscript; available in PMC 2013 September 01. 


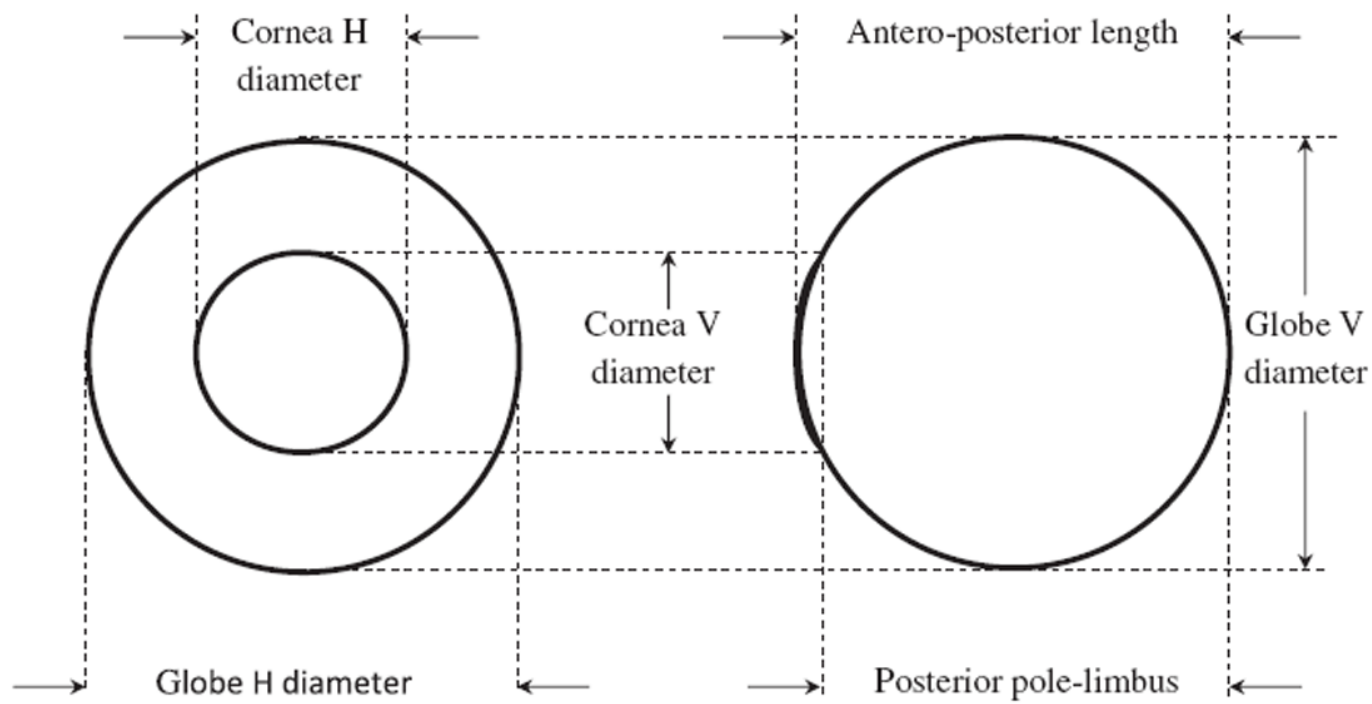

Fig. 1.

Diagrammatic representation of the ocular dimensions measured; coronal view on LHS and sagittal view on the RHS. Corneal curvature has been exaggerated in order to better show the measurement positions. 

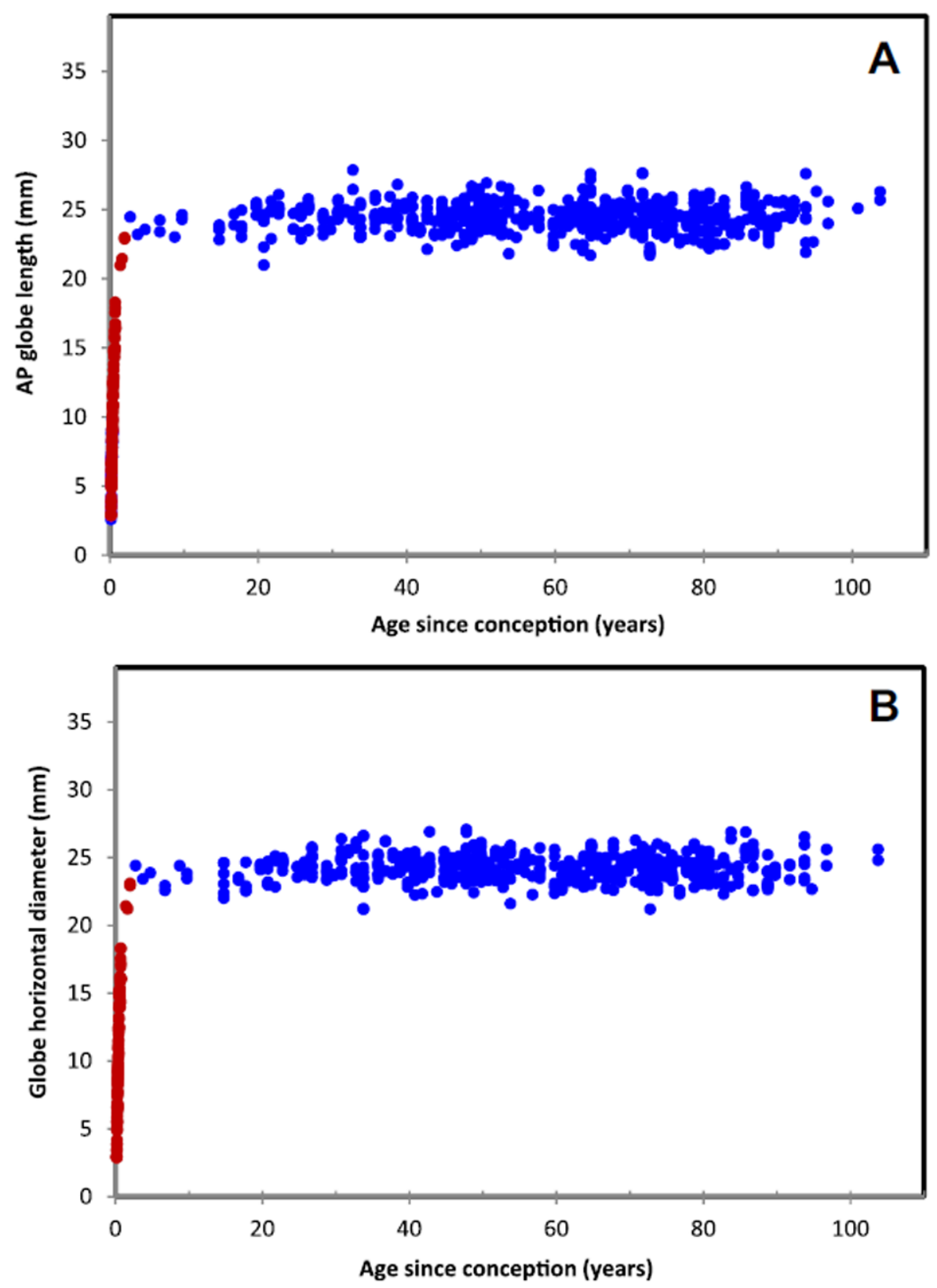

Fig. 2.

In vitro human globe dimensions as a function of age since conception ( $\bullet \bullet \bullet,<2$ years; $\bullet \bullet \bullet,>2$ years); A) Antero-posterior length (AP; $n=\mathbf{1 2 0}$ and 509, respectively); B) Horizontal diameter ( $H ; n=\mathbf{9 5}$ and 518, respectively). 


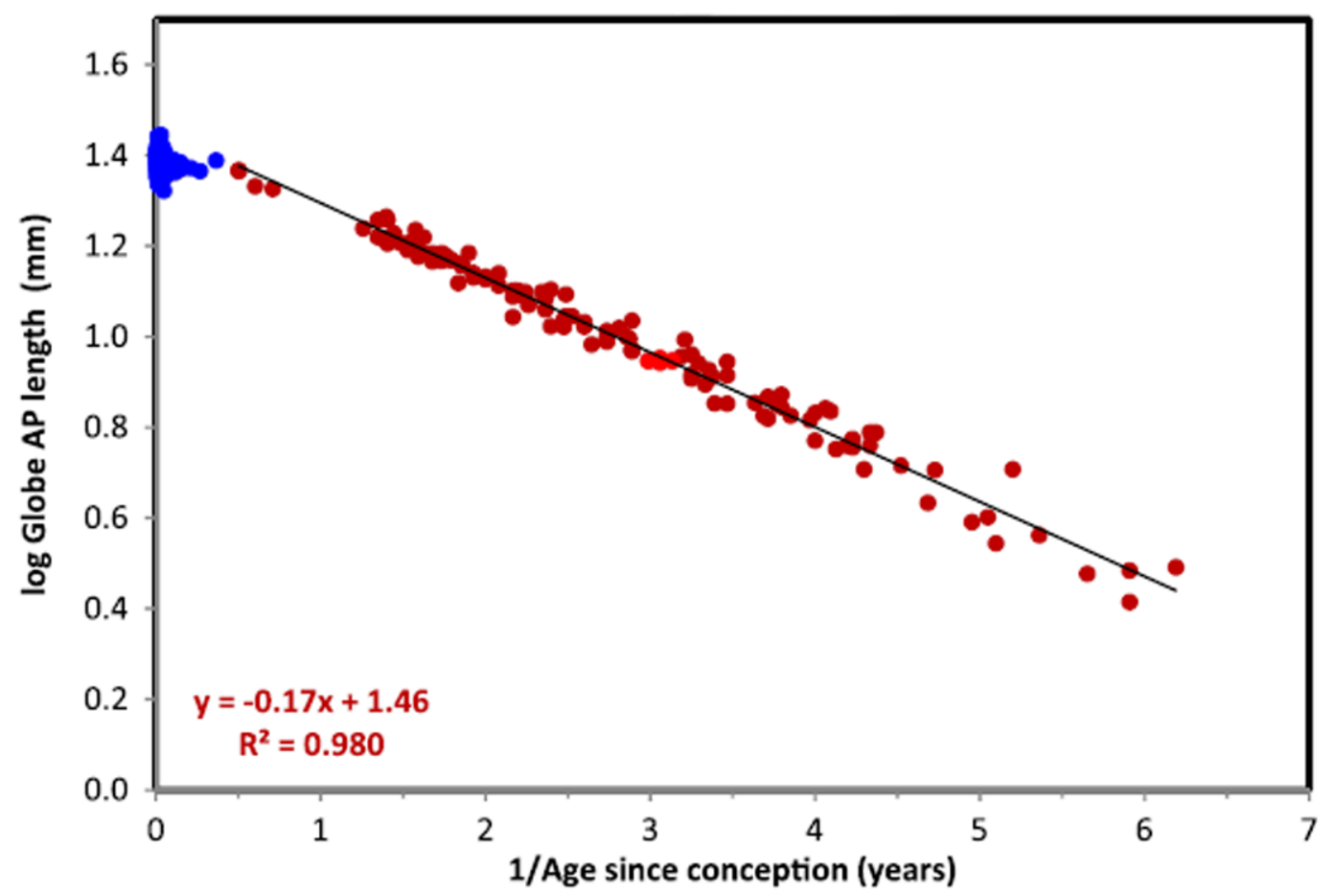

Fig. 3.

Logistic analysis of AP length as a function of age since conception $(\bullet \bullet \bullet,<2$ years; $n=$ 126: $\bullet \bullet \bullet,>2$ years; $n=661$ ). 

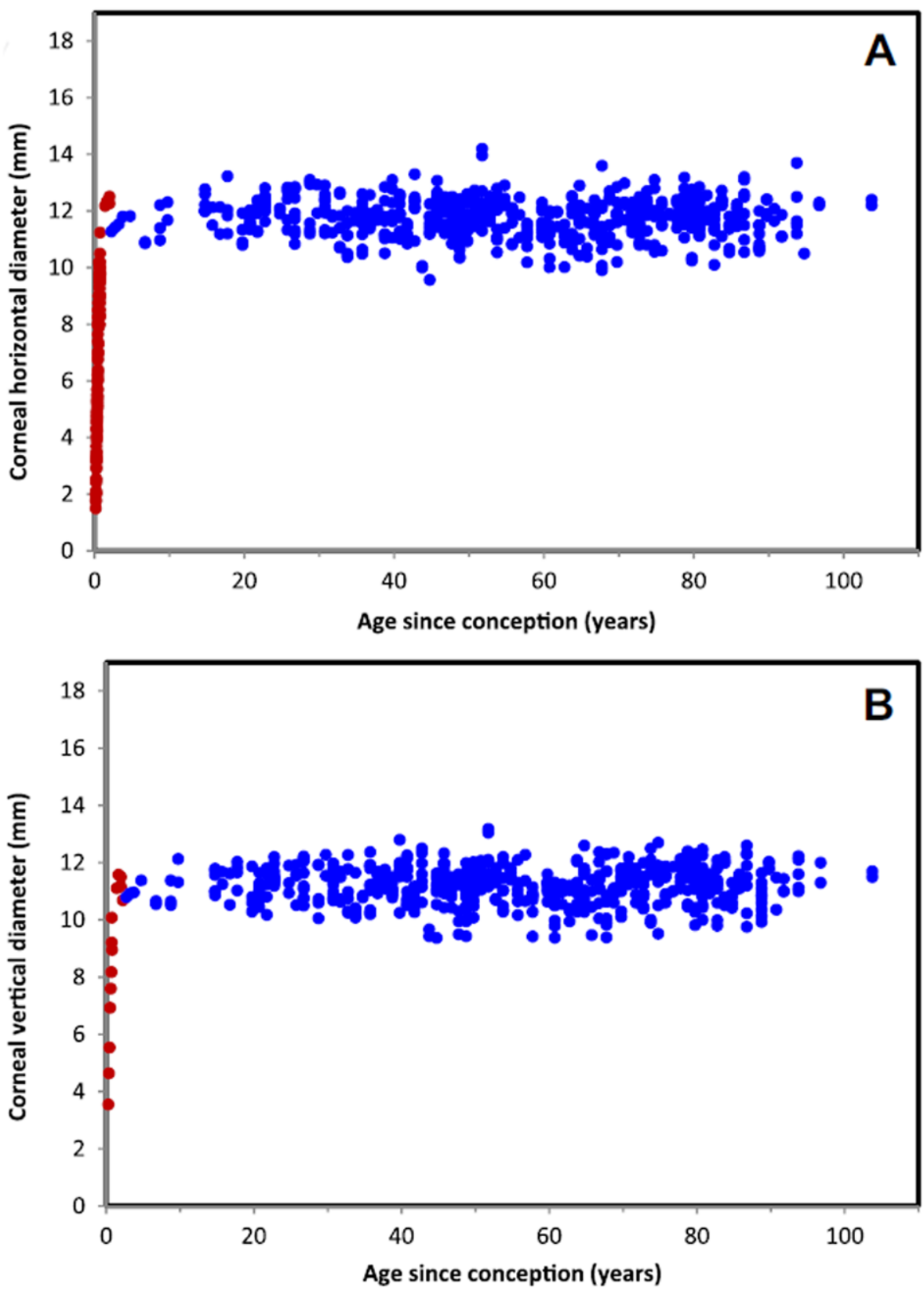

Fig. 4.

In vitro human cornea dimensions as a function of age since conception $(\bullet \bullet \bullet,<2$ years; $\bullet \bullet \bullet,>2$ years); A) Horizontal diameter ( $H ; n=\mathbf{1 4 4}$ and 503, respectively); B) Vertical diameter ( $V ; n=13$ and 496, respectively). 


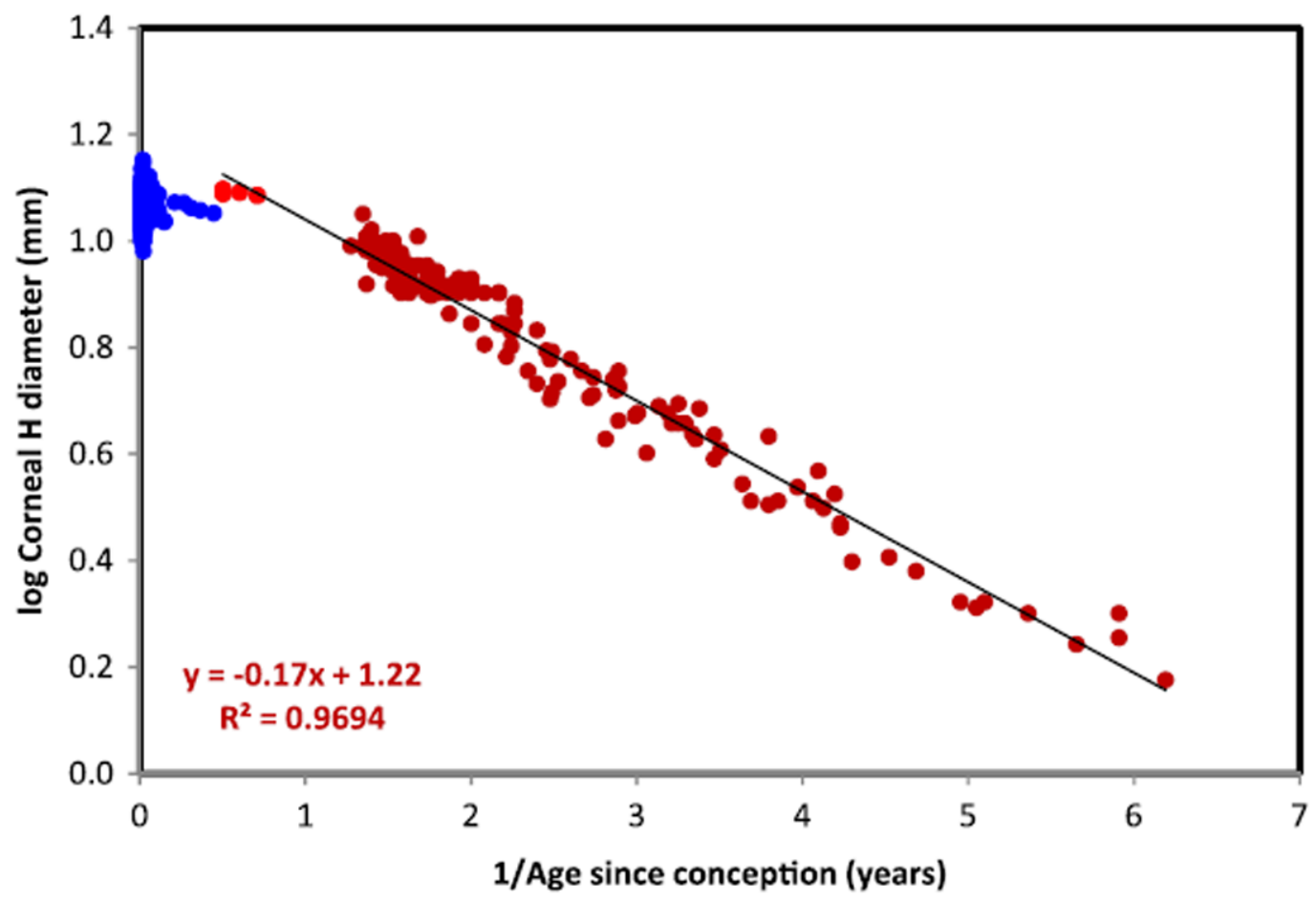

Fig. 5.

Logistic analysis of corneal horizontal diameter as a function of age since conception $(\bullet \bullet \bullet$, $<2$ years; $n=\mathbf{1 4 4}$ : $\bullet \bullet \bullet,>2$ years; $n=\mathbf{5 0 3}$ ). 


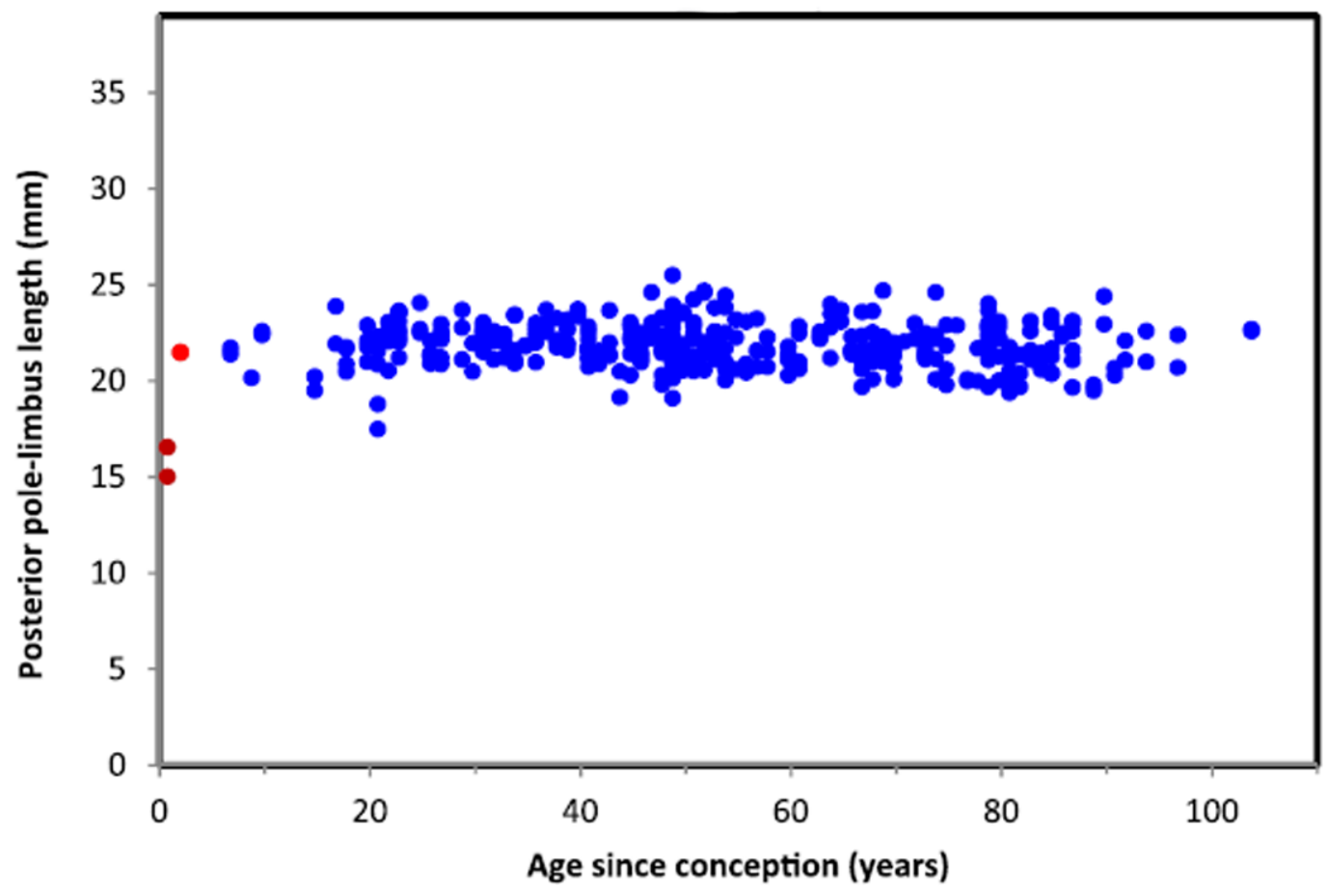

Fig. 6.

In vitro human posterior pole-limbus distance as a function of age since conception $(\bullet \bullet \bullet$, $<2$ years; $n=\mathbf{4}$ : $\bullet \bullet \bullet,>2$ years; $n=\mathbf{3 6 4}$ ). 

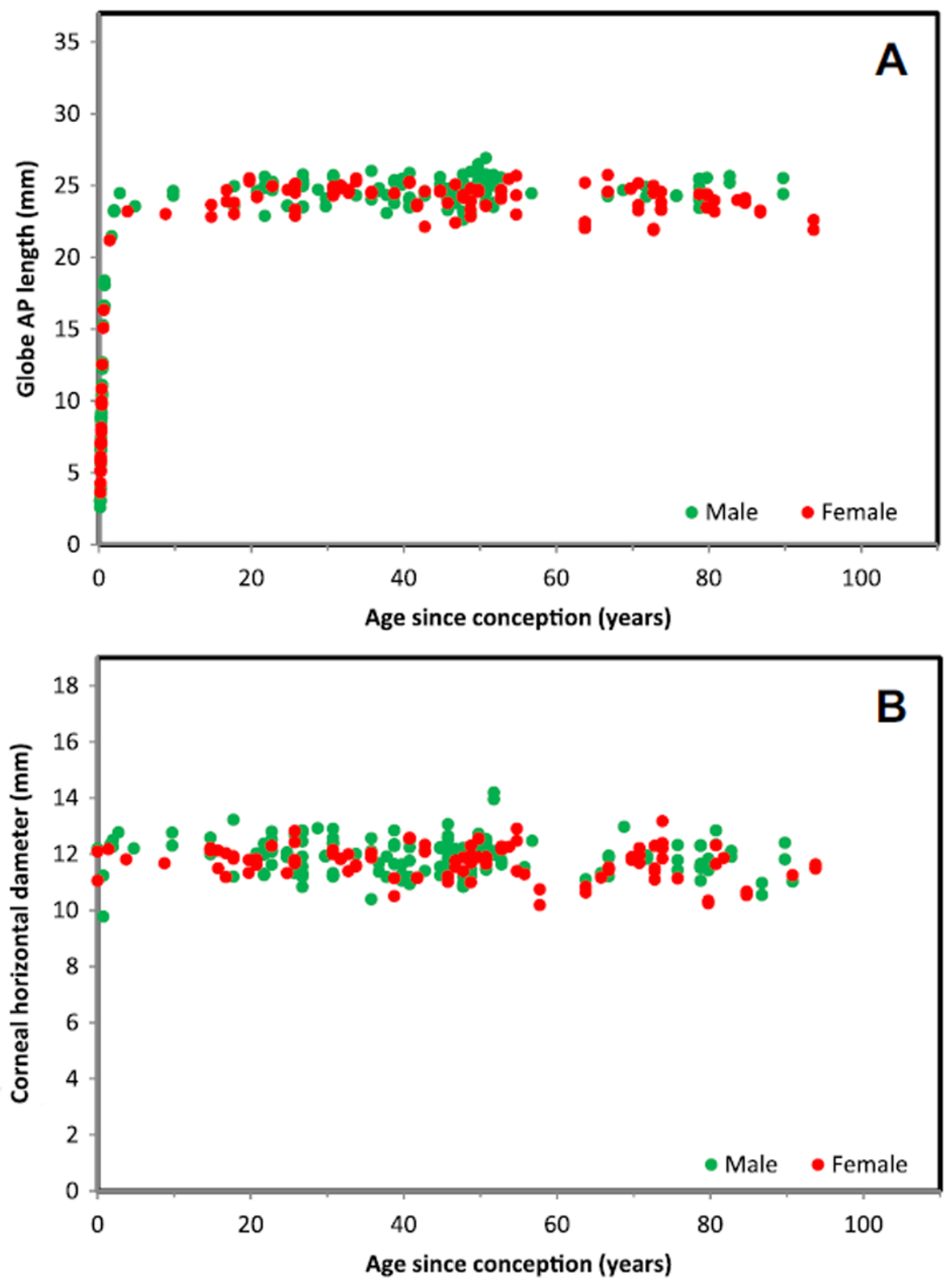

Fig. 7.

The influence of gender on A), AP length ( $\bullet \bullet \bullet$, male; $n=139$ : $\bullet \bullet \bullet$, female; $n=78$ ), and B), corneal horizontal diameter $(\bullet \bullet \bullet$, male; $n=169$ : $\bullet \bullet \bullet$, female; $n=108$ ). 